\title{
Análise do emprego do F-commerce como impulsionador do desempenho organizacional em micro e pequenas empresas no Brasil
}

\author{
André Andrade Longaray ${ }^{1}$, Cristian Reis Anselmo ${ }^{1}$, Claudia Maia ${ }^{1}$, Guilherme Lunardi ${ }^{1}$, \\ Paulo Munhoz ${ }^{1}$ \\ andrelongaray@gmail.com, cristian-reis@hotmail.com, claudiarmaia@hotmail.com, \\ gllunardi@furg.br, paulorsmunhoz@gmail.com \\ ${ }^{1}$ Universidade Federal do Rio Grande, Av. Itália, km o8, s/no ${ }^{\circ}$ CEP 96.203-90o, Rio Grande - RS, Brazil
}

DOI: 10.17013/risti.27.67-85

\begin{abstract}
Resumo: Em um cenário global de rápida e crescente ascensão do uso das mídias sociais como ambiente de negócios, este artigo apresenta os resultados da pesquisa conduzida com o objetivo de analisar como a utilização do Facebook Commerce pode impactar o desempenho de micro e pequenas empresas brasileiras. Metodologicamente, a pesquisa de caráter exploratório, foi conduzida por meio de um instrumento survey para a coleta de dados, os quais foram submetidos à análise de estatística descritiva e fatorial. Como resultados, foi possível verificar que as pressões externas são o principal fator motivador para adoção dessa modalidade de comércio social pelos gestores de micro e pequenas empresas. Os resultados indicaram, ainda, que o uso de uma rede social auxilia diretamente no desempenho dos processos dessas empresas.
\end{abstract}

Palavras-chave: Internet; Redes Sociais; Comércio Social; Facebook Commerce; Micro e Pequenas Empresas.

\section{Analysis of the use of F-commerce as a driver of organizational performance in micro and small enterprises in Brazil}

\begin{abstract}
In a global scenario of rapid and increasing rise in the use of social media as a business environment, this article presents the results of the research conducted with the objective of analyzing how the use of Facebook Commerce can impact the performance of micro and small Brazilians firms. Methodologically, the exploratory research was conducted by means of a survey instrument for the data collection, which were submitted to descriptive and factorial statistics analysis. As a result, it was possible to verify that external pressures are the main motivating factor for the adoption of this modality of social commerce by managers of micro and small companies. The results also indicated that the use of a social network directly assists in the performance of these companies' processes.
\end{abstract}

Keywords: Internet; Social networks; Social Commerce; Facebook Commerce; Small Business. 


\section{Introdução}

De acordo com dados do Serviço Brasileiro de Apoio às Micro e Pequenas Empresas (SEBRAE), até 2022, o Brasil terá cerca de 17,7 milhões de pequenos negócios, ou seja, mais de um milhão de novos empreendimentos por ano. Esse número é 43\% superior ao atual, que é de 12,4 milhões de Microempreendedores Individuais (MEI) e Micro e Pequenas Empresas (MPE) optantes do Simples Nacional, sistema que reduz a carga tributária e a burocracia (Pequenas empresas \& Grandes negócios, 2017). As MPE's no Brasil são classificadas de acordo com o número de empregados ou ainda pelo seu faturamento bruto anual. Os critérios estão descritos na Lei Complementar $\mathrm{n}^{0} 123$ de 14 de dezembro de 2006, a chamada Lei Geral das Microempresas e Empresas de Pequeno Porte (Brasil, 2006).

Atualmente, os pequenos negócios representam 98,5\% dos empreendimentos no país, respondem por mais de um quarto do Produto Interno Bruto (PIB) brasileiro e cerca de 12,4 milhões de optantes pelo Simples Nacional. Além disso, as micro e pequenas empresas são as principais geradoras de riqueza no Comércio no Brasil, já que respondem por 53,4\% do PIB desse setor. No PIB da Indústria, a participação das micro e pequenas empresas $(22,5 \%)$ já se aproxima das médias (24,5\%). E no setor de Serviços, mais de um terço da produção nacional (36,3\%) tem origem nos pequenos negócios (Pequenas empresas \& Grandes negócios, 2017). Para o Sebrae (2018), quando o empreendedor visualiza o mercado com todas as suas oportunidades e ameaças, vai em busca do melhor posicionamento diante dos concorrentes. A instituição afirma ainda que analisar a concorrência, saber suas forças e fraquezas e entender como o mercado está reagindo permite distinguir mais oportunidades.

Entre as oportunidades que podem surgir, destaca-se a utilização de redes sociais, definidas por Wasserman e Faust (1994) e Degenne e Forse (1999), como um conjunto de dois elementos: atores (pessoas, instituições ou grupos; os nós da rede) e suas conexões (interações ou laços sociais). As redes sociais abriram novas oportunidades, permitindo a comunicação de baixo custo e gerando benefícios para as empresas e para a população em geral, dada a facilidade de comunicação e a velocidade de difusão da informação (Belo et al., 2013). Recuero (2009) enfatiza que um dos aspectos mais populares para a compreensão das redes sociais na Internet é o estudo dos sites de redes sociais (SRSs). Para a referida autora, em uma perspectiva inicialmente adotada por Ellison, Steinfield e Lampe (2007), os sites de redes sociais são definidos como aqueles sistemas que permitem i) a construção de uma persona através de um perfil ou página pessoal; ii) a interação através de comentários; e iii) a exposição pública da rede social de cada ator.

Um fator que deve ser levado em consideraçãoé o marketing nas mídias sociais, entendido como sendo o conjunto de ações de marketing digital que buscam criar relacionamento entre a empresa e o cliente, para atrair a atenção desse e conquistar novos clientes no ambiente da internet (Torres, 2010). Quanto à publicidade online, Torres (2010) a descreve como um conjunto de ações de marketing com o objetivo de divulgar a marca e o produto da empresa, podendo ter similaridades com as convencionais, apesar de possuírem características próprias, como várias mídias e tecnologias, apresentando um público diferente para cada mídia e nem sempre fácil de determinar. Diante do exposto, este estudo busca responder o seguinte questionamento: as micro e pequenas empresas podem se beneficiar da utilização do Facebook-Commerce para impulsionar 
seu desempenho? A presença online atraiu mais atenção da comunidade científica na realização de pesquisas sobre redes sociais e seus benefícios para as organizações (Belo et al., 2013). Neste sentido, o trabalho tem como objetivo geral analisar os impactos da utilização do Facebook Commerce pelas micro e pequenas empresas no seu desempenho.

Para alcançar esse objetivo, tem-se como objetivos específicos: a) Descrever características da qualificação gerencial e características estruturais das micro e pequenas empresas participantes da pesquisa; b) Identificar motivos externos e internos que estão levando as MPE's a utilizarem o Facebook nos seus negócios; c) Identificar os benefícios obtidos pela utilização do Facebook aplicado aos negócios quanto ao seu desempenho; e d) Verificar a influência no desempenho da empresa a partir de informações disponibilizadas pelas ferramentas do F-Commerce.

Este artigo está organizado em 5 seções. Estabelecido o marco introdutório, a seção 2 descreve o referencial teórico que contextualiza e dá aporte científico ao trabalho. A seção 3 apresenta o delineamento metodológico da pesquisa. A seção 4 expõe os resultados da análise dos dados da amostra e a seção 5 tece as conclusões, limitações e contribuições da pesquisa, bem como sugestões para trabalhos futuros.

\section{Referencial Teórico}

Nesta seção apresenta-se o referencial teórico do trabalho, contextualizando o comércio social e o Facebook-commerce, destacando seus conceitos e características, de forma a fundamentar a proposta de pesquisa.

\subsection{Comércio Social}

O conceito de redes sociais, relacionado às tecnologias da informação, tem sua origem na Web 2.o. Isso corresponde a um conjunto de ferramentas e sites que permitem a colaboração e a participação de indivíduos. As redes sociais visam promover e apoiar o estabelecimento de relações virtuais entre indivíduos, entre organizações e entre indivíduos e organizações, e podem fomentar a criação de relações entre indivíduos que, em um ambiente não digital, não estabeleceriam nenhum tipo de vínculo (Martins et al., 2015).

A popularidade das redes sociais gerou inúmeras mudanças, tanto em termos sociais quanto econômicos, dando origem a um novo tipo de comércio eletrônico que tem modificado a forma como as compras online vêm sendo realizadas, chamado de comércio social (do inglês social commerce ou s-commerce) (Maia et al. 2018, Zhou; Zhang; Zimmermann, 2013; Chen; Shen, 2015). O comércio social refere-se ao uso das mídias sociais para realizar transações e atividades comerciais direcionadas principalmente pelas interações sociais e contribuições dos usuários (Liang; Ho; Li; Turban, 2011; Wang; Zhang, 2012). Dentro desse ambiente, os clientes têm acesso a conhecimentos e experiências sociais que os apoiam para entender melhor seu objetivo de compra online e tomar decisões de compra mais informadas e precisas (Huang; Benyoucef, 2015). As redes sociais vêm sendo usadas como local de troca de informação entre consumidores e também com as empresas (Soares; Dolci; Lunardi, 2015), possibilitando que o usuário exerça influência e também seja influenciado pela sua rede de amigos nas decisões de compras. 
Plataformas de comércio social são ferramentas com características tecnológicas únicas, pois refletem não só as propriedades objetivas, independente do cliente, mas também as propriedades subjetivas, ou seja, as percebidas pelo cliente. No comércio social, um cliente é exposto a vários recursos ou funções tecnológicas, assim como experiências de compra e avaliações, recomendações de outros perfis de usuário que desencadeiam o seu comportamento e participação em comércio social. Como é difícil medir o comportamento real, torna-se bastante comum medirem-se as intenções comportamentais, pois comprovadamente predizem o comportamento real (Zhang; Lu; Gupta; Zhao, 2014). De acordo com Souza e Schoeffel (2013), as redes sociais explodiram nos últimos anos, impactando no modelo de negócio das empresas. Conjuntamente a esse fato, o comércio eletrônico difundiu-se de forma acelerada. Empresas que ofertam seus produtos na Internet vão além de ações de promoção, propaganda, exposição e venda; elas introduzem novos conceitos e funcionalidades, podendo compartilhar conteúdos com sua rede de contatos, marcar como de interesse ou publicar informações pessoais. Para Turban, Bolloju e Liang (2010), o comércio social enfrenta algumas barreiras, destacando-se o pequeno número de visitantes ligados às empresas e de fãs nas redes sociais. A ênfase principal do comércio social é o marketing e sua orientação para vendas.

Souza e Schoeffel (2013) afirmam que existem duas formas onde os comércios podem fazer uso dessa perspectiva de negócios. Uma diz respeito ao uso da plataforma de rede social como loja dentro dessas mídias. A outra forma se relaciona ao emprego desses recursos de rede social na própria página da empresa.

Back (2012) afirma que cada vez mais micro e pequenas empresas estão investindo na presença digital, no entanto, são poucas aquelas que estão entrando neste meio de forma responsável. Para as empresas que desejam investir no meio digital, é importante que apliquem princípios relacionados ao planejamento (englobando aspectos do passado e do presente e, assim, garantir o preparo adequado para enfrentar o futuro); ao conteúdo (produzindo e compartilhando conteúdos relevantes para o seu público-alvo); ao relacionamento eficiente (fazendo com que o cliente seja "ouvido" e tenha respostas rápidas e profícuas quanto aos seus pedidos); e ao monitoramento (englobando as métricas e a importância de se ter dados confiáveis e mensuráveis para avaliar o retorno concreto das ações de marketing digital).

Para o E-Commerce News (2011), a maioria dos pequenos comerciantes utiliza-se das redes sociais para os negócios no meio digital pelos baixos custos operacionais, baixo consumo de tempo e/ou por ser eficaz na comunicação com os clientes. Outra vantagem das redes sociais é o fato desta complementar outros canais, sendo o Facebook a rede social mais utilizada pelas pequenas empresas.

\subsection{Facebook-commerce}

O advento do Facebook e da Web 2.0 levou ao nascimento de uma nova forma de negócio online, conhecida como Facebook commerce ou $f$-commerce (Jambulingamis et al. 2015; Kang; Johnson 2015; Liébana-Cabanillas; Alonso-Dos-Santos 2017). O F-commerce refere-se à compra e venda de bens ou serviços através do Facebook. Os profissionais de marketing começaram a usar o $f$-commerce para aprimorar a experiência de compra, ajudando na aquisição, lealdade e defesa do cliente. Derivado do e-commerce, o Facebook-Commerce é o uso do Facebook como uma plataforma para 
facilitar a execução e as operações de venda através do Facebook Open Graph. É o uso da mídia online, a qual suporta a interação social e as contribuições de usuários, para auxiliar na compra e venda online de produtos e serviços, com base nas experiências de outros usuários (Marsden, 2011).

O Facebook cresceu muito na última década e as empresas o estão utilizando para várias finalidades que incluem a construção de comunidades para gerar conversas e aumentar a base de fãs; para marketing e promoção, de modo a aumentar a conscientização sobre os próximos eventos ou vendas; e também para publicidade, a fim de aumentar o reconhecimento da marca. O f-commerce pode ser categorizado em dois grupos: 1) empresas que se conectam ao Facebook com aplicativos e páginas de fãs que trazem potenciais consumidores para seus sites e 2) empresas que se conectam ao Facebook por meio de páginas de fãs e aplicativos, e permitem que possíveis consumidores comprem diretamente de suas lojas do Facebook (Kang; Johnson, 2015). O objetivo principal dessas empresas é usar o Facebook para o engajamento do consumidor, para fazerem promoções de ofertas especiais e promover melhores interações sociais entre os consumidores e seus amigos. Devido à sua alta acessibilidade e baixo custo, as páginas de fãs do Facebook têm sido a principal plataforma através da qual os consumidores podem interagir e se comunicar com várias marcas (Martínez-Navarro; Bigné, 2017).

Para Martins (2014), há um detalhe no qual o empreendedor não pode se equivocar, que é a escolha entre página e perfil no Facebook. Existem diferenças que devem ser levadas em consideração, tais como: para o e-commerce e empresas de forma geral, é ideal que se opte por uma página, considerando que se trata de um ambiente específico para organizações, possibilitando interação e visibilidade maiores, além de transmitir profissionalismo e qualidade. De acordo com Porto (2012), a construção de uma loja no Facebook favorece a divulgação, através de recomendação e melhora a compreensão do público, uma vez que a participação dos fãs da marca é pública e, muitas vezes, permite descobrir comportamentos e opiniões que podem ajudar a aperfeiçoar as estratégias de vendas.

Para Braue (2011), o Facebook-Commerce oferece a capacidade de vincular preferências pessoais e padrões de compra em um processo relativamente simples: fotografar e descrever os produtos e seu conteúdo. A página no Facebook da empresa tornou-se um ponto de partida ativo e natural para os clientes que podem acessá-la de várias maneiras e, muitas vezes, voltam para verificar novos produtos ou promoções ou apenas para comentar sobre produtos comercializados online, sendo este o ponto crucial do Facebook-Commerce: além da capacidade de comprar produtos online, a possibilidade de conversar sobre os mesmos.

O comércio eletrônico oferece diferentes benefícios para empresas. Erazo, Castro e Achicanoy (2016) asseguram que reduz os custos gerados nos processos organizacionais, promovendo a abertura de novos mercados e melhorando a atenção de clientes novos e antigos. Em 2018, o comércio eletrônico deverá continuar apresentando um crescimento nominal acelerado, de 12\%, com faturamento de R \$ 53,5 bilhões. Assim como já aconteceu em 2017, a boa notícia para o setor é que o crescimento continuará sendo impulsionado pelo aumento do número de pedidos. Em 2017, 27,3\% das compras foram realizadas via smartphones ou tablets e até o final deste ano deve apresentar um crescimento robusto, passando a representar, no último trimestre, 37\% das compras (Ebit, 2018). Para 2018, a Ebit estima crescimento e espera chegar a mais de 60 milhões de compradores virtuais, 
número expressivo para o período. O relatório Webshoppers informa, ainda, que o crescimento do número de pedidos, em 2017, foi de 3,9\% em relação ao ano anterior, chegando a 50,3 milhões. Outra informação relevante apontada pelo relatório é a de que no Brasil 55 milhões de consumidores fizeram pelo menos uma compra virtual em 2017, representando assim um aumento de 15\%, se comparado a 2016.

As redes sociais são, então, uma opção para que as empresas maximizem sua presença na mente dos consumidores (Sebrae, 2017). O E-Commerce News (2013) aponta que "o fenômeno global do social commerce cresce rapidamente [...]. As mídias sociais continuam a oferecer aos consumidores do mundo inteiro novas formas de seduzir os clientes, engajar e aumentar a exposição de marcas e produtos", e empresas de todos os portes e segmentos estão atentas às tendências, assim como a novas ferramentas de social commerce. Segundo Lemos (2014), muitos pequenos empreendedores usam a Internet para vender seus produtos e até começam investindo unicamente nas vendas online para diminuir custos que teriam com uma loja física, o que não impede que isso seja feito de maneira profissional. O Facebook se mostra uma ferramenta indispensável para fidelizar o público, sendo ainda melhor para vender, possibilitando, com o Facebook Ads, comprar anúncios e segmentar o público-alvo, indo além de, simplesmente, impulsionar uma publicação.

\section{Metodologia}

Esta seção tem por intuito descrever o protocolo de pesquisa utilizado para o atingimento dos objetivos propostos. Nesse sentido, foi conduzida em duas etapas: uma exploratória e outra através de uma pesquisa survey. A etapa exploratória desta pesquisa deuse através de pesquisa qualitativa da literatura existente, sendo selecionados artigos desenvolvidos no Brasil e no exterior, disponíveis no banco de dados do Portal de Periódicos da Coordenação de Aperfeiçoamento de Pessoal de Nível Superior (CAPES) e do Google Acadêmico, além de sítios científicos que abordam temas relacionados às micro e pequenas empresas e outros dedicados à tecnologia e meios de comunicação.

A coleta de dados foi desenvolvida por meio de um questionário (Roesch, 2013). O instrumento desenvolvido foi composto por questões fechadas e teve como público respondente os empreendedores de micro e pequenas empresas, tendo o levantamento (survey) como método de investigação. Como técnica de análise dos dados, este trabalho utilizou a estatística univariada. De acordo com Roesch (2013), a análise univariada observa as frequências de cada questão pesquisada, permitindo uma comparação da amostra com a população, verificando a representatividade da amostra levantada. A forma de contato e envio dos questionários para os respondentes deuse através do Facebook, sendo estes escolhidos por conveniência. A fim de justificar a escolha da utilização do Facebook aplicado aos negócios, foram buscados modelos que compreendessem fatores internos e externos das organizações para atingir o desempenho organizacional desejado. O modelo desenvolvido por Lunardi, Dolci e Maçada (2010) foi escolhido visto sua estrutura, por ter sido desenvolvido com foco nas micro e pequenas empresas e por abordar temática próxima à ferramenta estudada neste trabalho.

No modelo de Lunardi, Dolci e Maçada (2010) foram identificados os construtos Utilidade Percebida, Necessidade Interna, Ambiente Organizacional e Pressões Externas como os principais motivos que levam as micro e pequenas empresas a adotarem a Tecnologia da 
Informação (TI). Na necessidade interna, a empresa adota a tecnologia para atender suas necessidades; no ambiente organizacional, a empresa adota a tecnologia por entender que possui um ambiente favorável à sua utilização; com relação às Pressões Externas, a empresa adota a tecnologia em função da concorrência, por exigência dos clientes, entre outros; e na Utilidade Percebida, a empresa adota a tecnologia porque percebeu que seria útil na realização de suas atividades (Lunardi; Dolci; Maçada, 2010).

Os autores chamam a atenção para os motivos que levam as empresas a adotarem a TI. Estes motivos impactam nos investimentos em equipamentos e sistemas utilizados, benefícios percebidos, nas dificuldades encontradas na adoção das tecnologias, assim como na realização de tais investimentos.

A validação do conteúdo das questões do questionário desenvolvido por Lunardi, Dolci e Maçada (2010) foi realizada em um grupo de 30 micro e pequenas empresas, mostrandose adequado. Em seguida, dois testes estatísticos foram realizados com os dados de 123 empresas respondentes: a análise fatorial e o Alfa de Cronbach, com o intuito de confirmar os quatro construtos: o ambiente organizacional, a utilidade percebida, necessidade interna e as pressões externas, como mostra a figura 1.

A partir do modelo de Lunardi, Dolci e Maçada (2010), aplicado ao contexto do Facebook-Commerce em micro e pequenas empresas, exploraram-se os fatores de adoção e as possíveis consequências do uso dessa tecnologia no desempenho organizacional. No entanto, é necessário observar a adequação dos construtos de adoção propostos no modelo ao objetivo de estudo deste trabalho. Para tanto, é necessário levar em consideração fatores que influenciam nas decisões, como as tarefas a serem desenvolvidas pela empresa no seu dia a dia; as ações da concorrência e exigência dos clientes; as condições do ambiente da empresa, a partir das suas características estruturais.

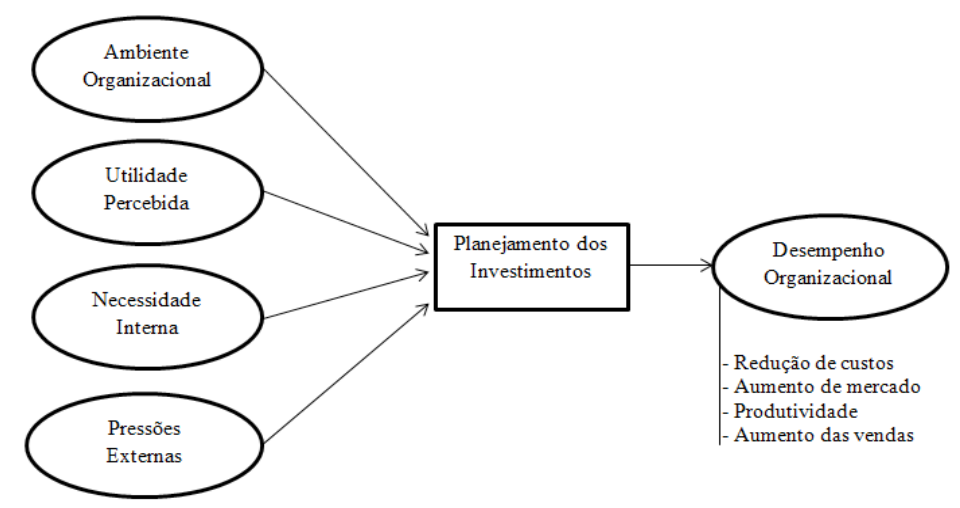

Figura 1 - Modelo teórico

Fonte: Adaptado de Lunardi; Dolci; Maçada (2010, p.12).

Surgem assim, como tentativa de respostas para o problema apresentado neste estudo, a partir das variáveis apresentadas no modelo, as seguintes hipóteses: 
H1: O Facebook, utilizado nos processos do negócio, auxilia no seu desempenho.

H2: As pressões externas influenciam as empresas a adotarem o Facebook-Commerce para impulsionar seu desempenho.

H3: A estrutura organizacional das MPE's configura-se como um diferencial para a utilização do Facebook como impulsionador do seu desempenho.

$\mathrm{O}$ instrumento de pesquisa divide-se em quatro seções. Na primeira parte, compreende informações gerais da amostra, como informações da empresa (porte, setor de atuação, número de funcionários, local de desenvolvimento de suas atividades, recurso para acessar a Internet, e se possui site próprio na Internet). Na segunda parte, busca informações gerais do proprietário ou gerente (gênero, faixa etária, nível de escolaridade). Na terceira parte, a partir do modelo adaptado, sugerem-se alguns dos principais motivos pelos quais as empresas passaram a utilizar o Facebook-Commerce, contendo uma lista de 10 questões fechadas, operacionalizadas em uma escala Likert de cinco pontos, variando entre: discordo totalmente a concordo totalmente. E, por fim, na quarta parte, propõem-se potenciais benefícios do uso do Facebook-Commerce pelas empresas, por meio de 12 questões fechadas e operacionalizadas em uma escala Likert de cinco pontos, variando entre: muito pouco a muitíssimo. Os quadros 1 e 2 apresentam as questões do instrumento. Partindo das três variáveis adaptadas a partir do modelo, as questões que os compreendem são distribuídas da seguinte forma: utilidade percebida (Q1, Q2, Q3, Q4, Q5, Q6, Q11, Q12, Q13, Q14, Q15, Q16, Q17); pressões externas (Q7, Q8, Q18, Q19); e estrutura organizacional (Q9, Q10, Q20, Q21, Q22). O instrumento é composto de questões adaptadas do trabalho de Lunardi; Dolci e Maçada (2010) e questões desenvolvidas levando em consideração o tema estudado.

\begin{tabular}{lll}
\hline Variáveis & Item & Sugestões de motivos para a adoção do Facebook nos negócios. \\
\hline & $Q 1$ & Para obter informações. \\
\cline { 2 - 3 } Utilidade Percebida & Para melhorar o atendimento aos clientes. \\
\cline { 2 - 3 } & $Q 3$ & Para aumentar as vendas. \\
\cline { 2 - 3 } & $Q 4$ & Para divulgar a empresa. \\
\cline { 2 - 3 } & $Q 5$ & Para divulgar seus produtos e/ou serviços. \\
\hline Pressões externas & $Q 6$ & Para aumentar o relacionamento da empresa com o cliente. \\
\hline Estrutura & $Q 8$ & Porque os concorrentes também têm utilizado. \\
\hline Organizacional & $Q 9$ & Para complementar outras formas de comunicação da empresa. \\
\hline
\end{tabular}

Fonte: Desenvolvido pelos autores.

Quadro 1 - Sugestões de motivos para a adoção do Facebook-Commerce 


\begin{tabular}{lll}
\hline Variáveis & Item & $\begin{array}{l}\text { Sugestões de potenciais benefícios da utilização do Facebook } \\
\text { nos negócios. }\end{array}$ \\
\hline & Q11 & Ajuda na obtenção de novos clientes. \\
\cline { 2 - 3 } Q12 & Facilita a obtenção de informações úteis à empresa. \\
\cline { 2 - 3 } U13 & Aumenta a capacidade de identificar problemas com antecedência. \\
\cline { 2 - 3 } & Q14 & Permite conhecer melhor os pontos fortes e fracos da minha empresa. \\
\cline { 2 - 3 } & Q15 & Permite a geração de informações que apoiam a tomada de decisão. \\
\hline Q16 & Auxilia no aumento das receitas da minha empresa. \\
\hline \multirow{2}{*}{ Pressões externas } & Q17 & Permite utilizar a informação gerada para fins estratégicos. \\
\hline \multirow{3}{*}{$\begin{array}{l}\text { Estrutura } \\
\text { Organizacional }\end{array}$} & Permite conhecer melhor a concorrência. \\
\hline & Q20 & Permite conhecer melhor os meus clientes. \\
\cline { 2 - 3 } & Q21 & Melhora a comunicação com os clientes. \\
\hline
\end{tabular}

Fonte: Desenvolvido pelos autores.

Quadro 2 - Sugestões de benefícios da utilização do Facebook-Commerce

\section{Resultados}

O questionário foi enviado por meio da rede social Facebook para as micro e pequenas empresas que disponibilizam seus produtos e/ou serviços na rede social, resultando em uma amostra de 110 empresas, caracterizada na Tabela 1.

\begin{tabular}{lll}
\hline Informações gerais da empresa & Total em números & Porcentagem \\
\hline Porte: & 84 & \\
\hline Micro empresa & 26 & $76,4 \%$ \\
\hline Empresa de pequeno porte & & $23,6 \%$ \\
\hline Setor em que atua: & 5 & $4,5 \%$ \\
\hline Indústria & 65 & $59,1 \%$ \\
\hline Comércio & 40 & $36,4 \%$ \\
\hline Serviços & 29 & $26,4 \%$ \\
\hline Número de funcionários, além do proprietário ou gerente: & 53 & $48,2 \%$ \\
\hline Nenhum & 16 & $14,5 \%$ \\
\hline 1 a 5 & 2 & $1,8 \%$ \\
\hline 6 a 10 & 5 & $4,5 \%$ \\
\hline 11 a 15 & 5 & $4,5 \%$ \\
\hline 16 a 20 & &
\end{tabular}




\begin{tabular}{lll}
\hline Informações gerais da empresa & Total em números & Porcentagem \\
\hline Principal local de desenvolvimento de suas atividades: & & \\
\hline Loja, oficina, fábrica, escritório & 74 & $67,3 \%$ \\
\hline Em casa & 24 & $21,8 \%$ \\
\hline Em local designado pelo cliente & 10 & $9,1 \%$ \\
\hline Em veículo automotor & 2 & $1,8 \%$ \\
\hline Via ou área pública & 0 & $0 \%$ \\
\hline A empresa possui como recurso de acesso à Internet: & & $2,7 \%$ \\
\hline Apenas telefone celular & 3 & $6,4 \%$ \\
\hline Apenas micro computador & 7 & $90,9 \%$ \\
\hline Micro computador e telefone celular & 100 & \\
\hline A empresa possui site na Internet? & & $59,1 \%$ \\
\hline Sim & 65 & $40,9 \%$ \\
\hline Não & 45 &
\end{tabular}

Fonte: Desenvolvido pelos autores.

Tabela 1 - Características das empresas respondentes

\begin{tabular}{lll}
\hline Informações do proprietário ou gerente & Total em números & Porcentagem \\
\hline Gênero: & 61 & \\
\hline Masculino & 49 & $55,5 \%$ \\
\hline Feminino & & $44,5 \%$ \\
\hline Faixa etária: & 0 & $0 \%$ \\
\hline Até 17 anos & 8 & $7,3 \%$ \\
\hline Entre 18 e 24 anos & 47 & $42,7 \%$ \\
\hline Entre 25 e 35 anos & 26 & $23,6 \%$ \\
\hline Entre 36 e 45 anos & 22 & $20 \%$ \\
\hline Entre 46 e 55 anos & 7 & $6,4 \%$ \\
\hline Superior a 55 anos & & \\
\hline Nível de escolaridade: & 5 & $4,5 \%$ \\
\hline Ensino fundamental incompleto & 2 & $1,8 \%$ \\
\hline Ensino fundamental completo & 1 & $0,9 \%$ \\
\hline Ensino médio incompleto & 20 & $18,2 \%$ \\
\hline Ensino médio completo & 22 & $20 \%$ \\
\hline Ensino superior incompleto & 60 & $54,5 \%$ \\
\hline Ensino superior completo ou mais & \\
\hline
\end{tabular}

Fonte: Desenvolvido pelos autores.

Tabela 2 - Características dos gestores 
Com relação aos proprietários ou gerentes das micro e pequenas empresas respondentes, suas características são mostradas na Tabela 2.

A validação do instrumento se deu através da técnica de análise fatorial, por meio do software Statistical Package for Social Sciences (SPSS) versão 20.0. No que tange à adequação da amostra, foi realizado o teste de Kaiser-Meyer-Olkin (KMO) e o teste de esfericidade de Bartlett. A extração de fatores ocorreu a partir do método de componentes principais. O procedimento de rotação utilizado foi o Varimax; e, por fim, verificou-se a confiabilidade da estrutura fatorial através do Alfa de Cronbach. Realizados os procedimentos estatísticos, a Tabela 3 apresenta, de forma resumida, os resultados obtidos. Nela, são apresentados os fatores encontrados com suas correspondentes cargas fatoriais em relação à estrutura completa e ao seu bloco de fator, a comunalidade $\left(\mathrm{h}^{2}\right)$ das variáveis, os autovalores (eigenvalue) de cada fator, o percentual da variância da amostra explicada por esses fatores, além dos índices de confiabilidade (Cronbach) e de apropriação da amostra (KMO e Bartlet). Na realização da análise houve a exclusão de cinco variáveis do instrumento, sendo excluídas as questões Q1, Q9, Q10, Q20 e Q22. Explica-se tal ação pela não conformidade do item ao fator encontrado para o mesmo, ao aspecto teórico do construto ou à baixa carga fatorial referente à variável.

Com relação à interpretação dos dados, através do teste KMO, conclui-se que a amostra possui tamanho adequado ao estudo fatorial. Como resultado, observou-se que a amostra possui uma boa adequação ao apresentar índice de 0,852. Já o teste de esfericidade de Bartlett indica que as correlações da amostra estudada são suficientes, visto que o nível de significância (p) é menor que 0,05. A extração de fatores é explicada pelo autovalor encontrado no método de componentes principais. Na análise, confirmase a presença de três fatores para a utilização do Facebook, visando potencializar o desempenho das micro e pequenas empresas, a partir do elevado autovalor destes componentes, sendo descritos na sequência.

Benefícios percebidos: esse construto, no arranjo após a análise fatorial, é composto pelas questões Q11, Q12, Q13, Q14, Q15, Q16, Q17, Q18, Q19 e Q21, as quais se referem aos potenciais benefícios do uso do Facebook utilizado nos negócios, na percepção dos micro e pequenos empresários, para atingir os objetivos estratégicos. Nas questões que tratam esse arranjo, partindo das publicações de informações referentes ao negócio na rede social, o gestor identificou aquelas que, na sua percepção, influenciaram nos seus objetivos estratégicos. O construto é responsável por aproximadamente 35,4\% da variância da amostra, apresentando um autovalor de 6,18. As variáveis que passaram a integrar esse fator apresentaram cargas fatoriais adequadas, tanto na análise da estrutura fatorial completa, quanto na análise por blocos. Com relação ao Alfa de Cronbach, o construto apresentou grau de confiança de 0,930. As comunalidades encontradas indicam uma aceitável variabilidade das questões, com índices variando de 0,557 a 0,757 entre as suas dez questões.

Motivações internas: o construto é composto pelas questões Q2, Q3, Q4, Q5 e Q6. Referem-se a alguns dos principais motivos pelos quais as empresas passaram a utilizar o Facebook-Commerce. No arranjo resultante da análise fatorial, agruparamse as questões com os motivos internos que podem influenciar o gestor na adoção da rede social para auxiliar nos processos da empresa, nos quais envolvem aspectos da organização e tomada de decisão. Esse construto corresponde a 25,4\% da variância 


\section{Variáveis}

\section{Benefícios percebidos}

Q17 - Permite utilizar a informação gerada para fins estratégicos.

Q15 - Permite a geração de informações que apoiam a tomada de decisão.

\begin{tabular}{|c|c|c|c|c|c|}
\hline Q16 - Auxilia no aumento das receitas da minha empresa. & ,800 &, 729 & & &, 736 \\
\hline Q11 - Ajuda na obtenção de novos clientes. & ,788 &, 722 & & &, 719 \\
\hline $\begin{array}{l}\text { Q13 - Aumenta a capacidade de identificar problemas com } \\
\text { antecedência. }\end{array}$ &, 781 &, 776 & & & ,672 \\
\hline Q12 - Facilita a obtenção de informações úteis à empresa. &, 780 &, 783 & & & ,628 \\
\hline Q19 - Permite conhecer melhor os meus clientes. &, 772 &, 737 & & &, 595 \\
\hline Q21 - Melhora o atendimento aos clientes. & ,759 &, 725 & & & 621 \\
\hline $\begin{array}{l}\text { Q14 - Permite conhecer melhor os pontos fortes e fracos da } \\
\text { minha empresa. }\end{array}$ &, 756 & ,759 & & & ,635 \\
\hline Q18 - Permite conhecer melhor a concorrência. &, 725 & ,671 & & &, 557 \\
\hline \multicolumn{6}{|c|}{ Motivações internas } \\
\hline Q4 - Para divulgar a empresa. & 957 & & ,956 & & 917 \\
\hline Q5 - Para divulgar seus produtos e/ou serviços. & ,928 & & ,933 & & ,874 \\
\hline Q3 - Para aumentar as vendas. & ,919 & & ,910 & & ,843 \\
\hline $\begin{array}{l}\text { Q6 - Para aumentar o relacionamento da empresa com o } \\
\text { cliente. }\end{array}$ & ,840 & & ,792 & &, 735 \\
\hline Q2- Para melhorar o atendimento aos clientes. &, 773 & &, 703 & & ,623 \\
\hline \multicolumn{6}{|c|}{ Motivações externas } \\
\hline Q7 - Porque os concorrentes também têm utilizado. & ,882 & & & ,869 &, 776 \\
\hline Q8 - Por influência dos clientes. & ,882 & & & ,799 & ,709 \\
\hline Autovalor (eigenvalue) & & 6,18 & 3,92 & 1,56 & \\
\hline Percentual de variância explicada (Total: 71,1\%) & & 35,4 & 25,4 & 10,3 & \\
\hline Alfa de Cronbach (Total: ,916) & & ,930 & ,918 &, 714 & \\
\hline
\end{tabular}

Teste KMO: ,852

Teste de esfericidade de Bartlett: qui-quadrado aproximado: 1533,809

Valor de p: o,oo

Fonte: Desenvolvido pelos autores.

Tabela 3 - Estrutura fatorial sumarizada

da amostra e apresenta autovalor igual a 3,92. Os itens pertencentes a esse construto apresentaram altas cargas fatoriais em relação à estrutura fatorial completa. As comunalidades apresentaram uma variabilidade entre 0,623 e 0,917 entre suas cinco questões. Em relação ao Alfa de Cronbach, esse também apresenta grau confiável (o,918), apresentando, também, boas cargas na análise realizada nos seus componentes. 
Motivações externas: Possui como componentes as questões Q7 e Q8, as quais estão agrupadas entre alguns dos principais motivos pelos quais as empresas passaram a utilizar o Facebook-Commerce, sendo influenciadas por pressões externas. Na percepção dos micro e pequenos empresários, a utilização da rede social também é motivada por influência de agentes externos à empresa, entre eles: clientes e concorrentes. Os itens desse construto correspondem a 10,3\% da variância da amostra, apresentando um autovalor de 1,56. Apresenta um autovalor menor se comparado aos anteriores e, consequentemente, o percentual representativo da variação de itens na amostra também é menor. Ainda assim, seus itens apresentaram altas cargas fatoriais (o,869 para Q7 e 0,799 para Q8). As comunalidades encontradas possuem valores próximos, sendo para Q7 de 0,776 e Q8 de 0,709. O Alfa de Cronbach apresentou grau de confiança de 0,714, apresentando também boas cargas na análise realizada nos seus blocos (o,882 para ambos os fatores). Juntos, os três fatores são responsáveis por $71,1 \%$ da variância total dos itens do instrumento. A análise fatorial foi realizada na estrutura completa, assim como em cada um dos três fatores obtidos. Apresentados e conceituados os construtos obtidos, decorre-se à análise descritiva dos mesmos, indicando, dessa forma, quais os aspectos mais impactantes na adoção do Facebook pelos gestores nos seus negócios. A Tabela 4 mostra a média aritmética,

\begin{tabular}{l|l|l}
\hline Item & Média & $\mathbf{S}$ \\
\hline Motivações internas & $\mathbf{4 , 5 3}$ & $\mathbf{0 , 7 1}$ \\
\hline Q4 - Para divulgar a empresa. & 4,71 & 0,71 \\
\hline Q5 - Para divulgar seus produtos e/ou serviços. & 4,69 & 0,71 \\
\hline Q3 - Para aumentar as vendas. & 4,59 & 0,75 \\
\hline Q6 - Para aumentar o relacionamento da empresa com o cliente. & 4,46 & 0,87 \\
\hline Q2- Para melhorar o atendimento aos clientes. & 4,20 & 1,00 \\
\hline Benefícios percebidos & $\mathbf{3 , 6 1}$ & $\mathbf{o , 9 0}$ \\
\hline Q16 - Auxilia no aumento das receitas da minha empresa. & 4,05 & 1,07 \\
\hline Q11 - Ajuda na obtenção de novos clientes. & 4,04 & 1,13 \\
\hline Q21 - Melhora o atendimento aos clientes. & 4,01 & 1,11 \\
\hline Q19 - Permite conhecer melhor os meus clientes. & 3,81 & 1,07 \\
\hline Q12 - Facilita a obtenção de informações úteis à empresa. & 3,76 & 1,14 \\
\hline Q17 - Permite utilizar a informação gerada para fins estratégicos. & 3,65 & 1,19 \\
\hline Q18 - Permite conhecer melhor a concorrência. & 3,44 & 1,22 \\
\hline Q15 - Permite a geração de informações que apoiam a tomada de decisão. & 3,25 & 1,16 \\
\hline Q13 - Aumenta a capacidade de identificar problemas com antecedência. & 3,08 & 1,22 \\
\hline Q14 - Permite conhecer melhor os pontos fortes e fracos da minha empresa. & 3,05 & 1,17 \\
\hline Motivações externas & $\mathbf{3 , 0 8}$ & $\mathbf{1 , 0 8}$ \\
\hline Q8 - Por influência dos clientes. & 3,08 & 1,26 \\
\hline Q7 - Porque os concorrentes também têm utilizado. & 3,07 & 1,19 \\
\hline
\end{tabular}

Fonte: Desenvolvido pelos autores.

Tabela 4 - Análise descritiva dos fatores e itens 
o desvio-padrão (s) de cada fator e os respectivos itens correspondentes. A partir dos dados obtidos na análise descritiva, pode-se interpretar que os micro e pequenos empresários, ao visar um melhor desempenho do seu negócio, utilizam o Facebook-Commerce, na maioria das vezes, motivados por fatores internos. Essa afirmativa é embasada pelo valor apresentado para o construto "motivações internas", com média encontrada de 4,53 entre as respostas. Nesse construto, pode-se encontrar aquele que apresentou a maior média dentre todos e que a utilização do Facebook, aplicado aos negócios pelas MPE's, consolida-se com o intuito de divulgação da empresa, apresentando média de 4,71. Muito próximo desse valor, outro motivo que se pode destacar é a utilização da rede social para divulgação dos produtos e/ou serviços da empresa (com média de 4,69).

Em busca de um melhor desempenho da organização, outra motivação interna é observada através da questão Q3, a qual sugere que as empresas utilizam a plataforma com a finalidade de aumentar suas vendas, obtendo média de respostas de 4,59. Outras motivações internas seriam a utilização da rede social para aumentar o relacionamento da empresa com seus clientes, com 4,46 de média das respostas, bem como melhorar o atendimento aos clientes $(4,20)$. Analisando o próximo construto, com média geral de 3,61, esse busca identificar, na percepção dos gestores, os benefícios que a utilização do Facebook-Commerce traz para suas estratégias de desempenho. Como benefício principal constatado nesse fator, percebeu-se por parte dos micro e pequenos empresários que a utilização da ferramenta auxilia no aumento das receitas das empresas, apresentando média de 4,05 entre as respostas. Outro benefício que pôde ser identificado a partir das respostas da amostra pauta-se no fato de que a utilização da ferramenta ajuda na obtenção de novos clientes, apresentando média de 4,04. Foi possível identificar, também, que a rede social, com 4,01 de média entre as respostas, melhora o atendimento aos clientes. Prosseguindo com a análise, no que tange à percepção dos gestores, estes entendem que a utilização do Facebook-Commerce permite que se obtenha um melhor conhecimento de seus clientes (média de 3,81); com relação aos benefícios do Facebook no desempenho de suas empresas, percebe-se, também, que ela permite a obtenção de informações úteis à empresa, com média de 3,76 entre os respondentes. $\mathrm{O}$ fato de utilizar as informações geradas para fins estratégicos é percebida com 3,65 da média de respondentes. Apresentando médias de menor intensidade, surge a utilização da rede social com o intuito de conhecer melhor a concorrência (Q18 = 3,44 de média). Outra utilização com mesma característica de média converge na ideia de que sua utilização permite a geração de informações que apoiam a tomada de decisão $(\mathrm{Q} 15=3,25)$. Por último, com relação aos benefícios identificados pelo micro e pequenos empresários, apresentaram como média de 3,08 e 3,05, respectivamente, as questões Q13 e Q14. Essas afirmam que a utilização do Facebook nos negócios aumenta a capacidade de identificar problemas com antecedência, assim como permite conhecer melhor os pontos fortes e fracos do negócio. Por fim, analisando o último construto obtido, esse apresentou média de 3,08. Pode-se constatar, assim, que a utilização do Facebook-Commerce é pouco influenciada por motivações externas. Entre as pressões externas sugeridas, a adoção da rede social pelas MPE's por influência dos clientes apresentou média de 3,08 entre os empresários respondentes. Quanto à adoção justificar-se pelo fato da concorrência também utilizar a rede social, esse fator apresentou média de 3,07 entre os respondentes.

Com base nos resultados apresentados, confirma-se a primeira hipótese levantada considerando o problema desta pesquisa - H1: O Facebook, utilizado nos processos do 
negócio, auxilia no seu desempenho. Sua utilização auxilia no desempenho dos processos das organizações estudadas. Essa hipótese é confirmada através da média das respostas para os itens Q11, Q12, Q13, Q14, Q15, Q16, Q17, Q18, Q19 e Q21, componentes dos fatores que analisam os benefícios percebidos sugeridos na pesquisa aplicada aos gestores. Confirmase, também, a segunda hipótese deste trabalho - H2: As pressões externas influenciam as empresas a adotarem o Facebook-Commerce para impulsionar seu desempenho. Devido às pressões externas, as empresas são influenciadas a utilizarem o Facebook-Commerce para impulsionar seu desempenho. Como mostram os resultados, essas motivações externas decorrem de pressões exercidas pelos clientes e pelo fato da concorrência também utilizar esse recurso, situação demostrada pelas questões Q7 e Q8. Como conclusão para a terceira hipótese - H3: A estrutura organizacional das MPE's configura-se como um diferencial para a utilização do Facebook como impulsionador do seu desempenho. Não se pôde confirmar essa hipótese na pesquisa desenvolvida. Situações entendidas como características desse fator apresentaram não conformidade ao aspecto teórico do fator obtido após análise ou baixa carga fatorial, sendo excluídas da análise.

\section{Conclusões}

Nesta pesquisa, explorou-se a relação existente entre a adoção do Facebook-Commerce e o impacto percebido no desempenho organizacional das micro e pequenas empresas. Verificou-se que as MPE's são motivadas por três diferentes fatores: motivações internas, benefícios percebidos e motivações externas. Traçando um comparativo com o trabalho de Lunardi, Dolci e Maçada (2010), seus estudos encontraram como principal fator para a utilização da TI nas micro e pequenas empresas a influência de pressões externas. Nesta pesquisa, entende-se que o principal motivo para a utilização do Facebook nos negócios se dá por motivações internas.

Com relação à utilidade percebida, os autores destacam que esse fator não se mostrou significativo para a adoção de TI, demonstrando preocupação para o resultado. Para a pesquisa desenvolvida com a rede social, os benefícios percebidos pelos gestores são apresentados como o segundo fator mais relevante para a sua adoção, visando um melhor desempenho organizacional. Para os estudos sobre TI, as pressões externas são os principais fatores que motivam as organizações a informatizarem-se. No que tange à adoção do Facebook pelas micro e pequenas empresas nas suas estratégias, as motivações externas foram as que apresentaram menor significância na análise das respostas dos gestores. Quanto às informações obtidas nesta pesquisa, destaca-se a média de respondentes que passaram a utilizar o Facebook-Commerce influenciados por motivações internas. Como principais razões para a sua utilização, encontram-se a divulgação da empresa, dos seus produtos e/ou serviços, para aumentar as vendas, aumentar o relacionamento e o atendimento da empresa com seus clientes. Entre os principais benefícios percebidos, destaca-se o aumento das receitas, a obtenção de novos clientes e a melhoria do atendimento aos clientes. A utilização da plataforma para os negócios é influenciada de forma razoável, também, como descrito anteriormente, por agentes externos, seja pelo fato dos concorrentes a utilizarem ou por exigência dos clientes. A partir dos resultados obtidos, confirma-se a primeira e a segunda hipótese levantadas, percebendo-se que a rede social auxilia diretamente no desempenho dos processos das MPE’s; assim como sua utilização se dá, também, por motivações 
externas, mesmo essa situação apresentando menor relevância. Com relação à hipótese de que a estrutura das organizações configura um diferencial para a utilização da rede social, descarta-se tal situação por não apresentar influência na análise realizada. Como contribuição, este trabalho procura demonstrar um panorama da utilização do Facebook visando um melhor desempenho dos micro e pequenos negócios, levando em consideração sua popularidade e crescimento no número de usuários. Mostra que seu potencial deve ser cada vez mais explorado pelos gestores, devido à sua praticidade, baixos custos e por permitir um contato maior com seus clientes.

Sugere-se, a título de novas pesquisas, a realização do estudo das três hipóteses aqui propostas, mas em outra forma de mídia social. Outra possibilidade é a aplicação do survey elaborado para esta pesquisa em uma população de usuários de rede social de outra região geográfica (usuários de outro país ou outro continente).

\section{Referências}

Belo, A., Castela, G., \& Fernandes, S. (2013). Collaborative Virtual Environments: potential of social networks. The case of companies in the Algarve. RISTI - Revista Ibérica de Sistemas e Tecnologias de Informação, (12), 65-79. Doi: 10.4304/ risti.12.65-79

Back, C. (2012) Os 4 pilares do marketing digital para pequenas empresas. Acesso em: 24 maio 2015. Sítio web://blogmidia8.com/2012/o1/os-4-pilares-do-marketingdigital-para.html.

Brasil. (2006). Lei Complementar $\mathrm{n}^{\mathrm{o}}$ 123, de 14 de dezembro de 2006. Institui o Estatuto Nacional da Microempresa e da Empresa de Pequeno Porte, e dá outras providências. Brasília: Diário Oficial da República Federativa do Brasil.

Braue, D. (2011) Facebook Commerce F Is The New E. APC (Bauer Media Group), 31(10), 14-17. Sítio web: http://search.ebscohost.com/login.aspx?direct=true\&db=iih\&A $\mathrm{N}=66436582 \&$ lang=pt-br\&site=ehost-live. Acesso em: 28 maio 2015 .

Chen, J., \& Shen, X. (2015). Consumers' decisions in social commerce context: An empirical investigation. Decision Support Systems, 79, 55-64. Doi: 10.1016/j. dss.2015.07.012

Degenne, A., \& Forsé, M. (1999). Introducing Social Networks. London: Sage.

Ebit. (2018). Relatório Webshoppers 37. ed. E-Bit. Sítio web: https://pt.slideshare.net/ LucasModesto6/webshoppers-37-2018. Acesso em 23/06/2018.

E-Commerce News (2011). Baixo custo operacional leva o pequeno empresário às mídias sociais. Sítio web: http://ecommercenews.com.br/noticias/pesquisasnoticias/baixo-custo-operacional-leva-o-pequeno-empresario-as-midias-sociais. Acesso em: 17 maio 2015.

E-Commerce News (2013). SOCIAL Commerce: como mensurar o impacto da mídia social no meu negócio? Sítio web: http://ecommercenews.com.br/noticias/ pesquisas-noticias/social-commerce-como-mensurar-o-impacto-da-midia-socialno-meu-negocio. Acesso em: o1 jun. 2015. 
Ellison, N. B., Steinfield, C., \& Lampe, C. (2007). The benefits of Facebook "friends:" Social capital and college students' use of online social network sites. Journal of ComputerMediated Communication, 12(4), 1. Sítio web: http://jcmc.indiana.edu/ vol12/issue4/ellison.html. Doi: 10.1111/j.1083-6101.2007.00367.x

Erazo, S., C. R., Castro, A. A., \& Achicanoy, H. A. (2016). Inversión en Tecnologías de la Información y las Comunicaciones y su relación con en el direccionamiento estratégico de las PYMES de Santiago de Cali-Colombia. RISTI-Revista Ibérica de Sistemas e Tecnologias de Informação, (18), 01-17. doi:10.17013/risti.18.1-17

Huang, Z., \& Benyoucef. M. (2015). User preferences of social features on social commerce websites: an empirical study. Technological Forecasting and Social Change, 95, 57-72. Doi: 10.1016/j.techfore.2014.03.005

Jambulingamis, M., Sumathi, C., \& Rajagopal, G. R. (2015). Barriers of venturing into Facebook commerce among SMEs. The Journal of Internet Banking and Commerce, 2(8): o-o. Sítio web: http://www.icommercecentral.com

Kang, J.Y.M., \& Johnson, K.K. (2015). F-Commerce platform for apparel online social shopping: Testing a Mowen's 3M model. International Journal of Information Management, 35(6), 691-701. Doi: 10.1016/j.ijinfomgt.2015.07.004

Lemos, M. (2014). 6 coisas indispensáveis para um negócio online. Sítio web: http://www.ferramentasblog.com/2014/12/6-coisas-indispensaveis-para-umnegocio-online.html. Acesso em: 01 jun. 2015.

Liang, T. P., Ho, Y. T., Li, Y. W., \& Turban, E. (2011). What drives social commerce: The role of social support and relationship quality. International Journal of Electronic Commerce, 16(2), 69-90. Doi: 10.2753/JEC1086-4415160204

Liébana-Cabanillas, F., \& Alonso-Dos-Santos, M. (2017). Factors that determine the adoption of Facebook commerce: The moderating effect of age. Journal of Engineering and Technology Management, 44(1), 18. Doi: 10.1016/j. jengtecman.2017.03.001

Lunardi, G. L., Dolci, P. C., \& Maçada, A. C. G. (2010). Adoção de tecnologia de informação e seu impacto no desempenho organizacional: um estudo realizado com micro e pequenas empresas. Revista de Administração, 45(1), 5-17. doi: 10.1016/ Soo80-2107(16)30505-2

Maia, C., Lunardi, G., Longaray, A., \& Munhoz, P. (2018). Factors and characteristics that influence consumers' participation in social commerce. Revista de Gestão, 25(2), 1-18. Doi: 10.1108/REGE-03-2018-031

Marsden, P. (2011). The F-Commerce FAQ. Sítio web: http://digitalintelligencetoday. com/f-commerce-faq-all-you-ever-wanted-to-know-about-facebook-commercebut-were-afraid-to-ask/. Acesso em: 25 maio 2015.

Martínez-Navarro, J., \& Bigné, E. (2017). The value of marketer-generated content on social network sites: media antecedents and behavioral responses. Journal of Electronic Commerce Research, 18(1), 52-72. Sítio web: http://www.jecr.org/ sites/default/files/2017vol18no1_Paper4.pdf 
Martins, F. (2014). Página x perfil: como usar o Facebook no e-commerce?. E-Commerce News. Sítio web: http://ecommercenews.com.br/artigos/tutoriais/pagina-X-perfilcomo-usar-o-facebook-no-e-commerce. Acesso em: 25 maio 2015.

Martins, J., Gonçalves, R., Santos, V., Cota, M., Oliveira, T., \& Branco, F. (2015). A Proposal for a Social e-Learning Model2. RISTI - Revista Ibérica de Sistemas e Tecnologias de Informação, (16), 92-107. Doi: 10.17013/risti.16.92-107

Pequenas empresas \& Grandes Negócios (2017). Em Cinco Anos, Número De Pequenos Negócios Crescerá 43\%. Sítio web: https://revistapegn.globo.com/ Empreendedorismo/noticia/2017/10/em-cinco-anos-numero-de-pequenosnegocios-crescera-43.html.

Porto, F. (2012). F-Commerce: a revolução das lojas virtuais no Facebook. Tec Triade Brasil. Sítio web: http://tectriadebrasil.com.br/blog/f-commerce-a-revolucao-daslojas-virtuais-no-facebook/. Acesso em: 31 maio 2015.

Recuero, R. (2009). Redes sociais na internet. Porto Alegre: Sulina. Coleção Cibercultura, 191.

Roesch, S. M. A. (2013). Projetos de estágio e de pesquisa em administração: guia para estágios, trabalhos de conclusão, dissertações e estudos de caso. 3.ed. São Paulo: Atlas.

Sebrae (2017). Venda mais usando as redes sociais. Sítio web: http://www.sebrae. com.br/sites/PortalSebrae/artigos/O-e\%E2\%80\%93commerce-nas-redes-sociais. Acesso em: 01 jan. 2018.

Sebrae (2018). Analise o mercado antes de tomar decisões. Sítio web: http://www.sebrae.com.br/sites/PortalSebrae/artigos/analise-o-mercado-antesde-tomar-decisoes,50od7eo805b1a410VgnVCM1000003b74010aRCRD. Acesso em: 01 mar. 2018.

Soares, M., Dolci, D., \& Lunardi, G. (2015). S-Commerce: um Experimento sobre Variáveis Moderadoras da Relação de Influência da Recomendação na Confiança. Anais do Encontro Nacional da Associação Nacional de Pós-Graduação e Pesquisa em Administração, Rio de Janeiro, RJ, Brasil, 39.

Souza, M., \& Schoeffel, P. (2013). Panorama atual do social commerce no Brasil. REAVI-Revista Eletrônica do Alto Vale do Itajaí, 2(2), 161-164. Sítio web: http://www.revistas.udesc.br/index.php/reavi/article/view/406o/2919. Acesso em: 17 maio 2015 .

Torres, C. (2010). Guia Prático de Marketing na Internet para Pequenas Empresas: dicas para posicionar o seu negócio e conquistar novos clientes na Internet. Sítio web: http://www.cairu.br/biblioteca/arquivos/Marketing/Marketing_Internet_ TORRES.pdf

Turban, E., Bolloju, N., \& Liang, T. P. (2010). Social commerce: an e-commerce perspective. In Proceedings of the 12th International Conference on Electronic Commerce: Roadmap for the Future of Electronic Business (pp. 33-42). ACM. Doi: 10.1145/2389376.2389382 
Wang, C., \& Zhang, P. (2012). The evolution of social commerce: The people, management, technology, and information dimensions. Communications of the Association for Information Systems, 31(5), 1-23. Sítio web: http://aisel.aisnet. org/cais/vol31/iss1/5

Wasserman, S., \& Faust, K. (1994). Social Network Analysis. Methods and Applications. Cambridge, UK: Cambridge University Press.

Zhang, H., Lu, Y., Gupta, S., \& Zhao, L. (2014). What motivates customers to participate in social commerce? The impact of technological environments and virtual customer experiences. Information \& Management, 51(8), 1017-1030. Doi: 10.1016/j. im.2014.07.005

Zhou, L., Zhang, P., \& Zimmermann, H. D. (2013). Social commerce research: An integrated view. Electronic commerce research and applications, 12(2), 61-68. Doi: 10.1016/j.elerap.2013.02.003 